\title{
Many Unknowns of Lithium Ion Battery Safety in Aerospace
}

\author{
Dr. Heather L Garten
}

\begin{abstract}
Aviation continues to rapidly develop through ground-breaking technological and manufacturing feats. Specifically, the aircraft being delivered and manufactured today are evolving at an exponential rate, demanding innovative technology and manufacturing. From inflight wireless internet (Wi-Fi) to a light weight fuselage made with advanced composites to cabins that mimic living rooms of the rich and famous, the aircraft of today have very little resemblance to those just a decade ago. These aircraft demand more power, and the aviation and aerospace industries demand minimal costs. Thus why the aviation and aerospace industries began using lithium ion batteries. Lithium ion batteries are a common household item as they provide lightweight and intense power for cell phones, computers, power tools, and many other devices. However, lithium ion batteries, although light and powerful, have many draw-backs. The most notable is their fire hazards, which earned these batteries a great deal of press in early 2013 through their aerospace applications at Boeing. This paper focuses on the 2013 lithium ion battery fires aboard Boeing's 787 Dreamliner aircraft and the UPS Dubai tragedy, offering a brief overview of the composition of lithium ion batteries to demonstrate the dangers of potential chemical interactions during battery fires. This paper concludes with possible new alternatives to these small energy powerhouses. The goal of this paper is to demonstrate how the present and future of lithium ion batteries remains uncertain as potential fire hazards increase with every aircraft innovation.
\end{abstract}

Keywords-Aerospace, Aviation, Battery Fire, Boeing 787 Dreamliner, Hazardous Material, Lithium ion battery

\section{INTRODUCTION}

In the early 1980 s the demand for lightweight, rechargeable batteries began to increase. This increase was a result of the electronics industry beginning to take flight into the age of technology, ignited by production of portable devices such as stereos and phones. Demand for these cutting-edge portable electronic devices quickly escalated, as thus did the demand for light-weight rechargeable batteries [18].

The most common batteries used up until the 1980s were lead-acid base and nickel cadmium. These batteries are known as aqueous since water is the electrolyte used for these batteries. Aqueous batteries have an inherent disadvantage as around $1.5 \mathrm{~V}$ the water and the electrolyte begin to separate via electrolysis (the maximum energy on each cell is approximately $1.5 \mathrm{~V}$ ). Hence the ability to create a more powerful and small aqueous battery is currently thought to be limited [18].
Due to the limitations with the aqueous batteries, researchers in the 1980s began experimenting with nonaqueous batteries since they can achieve power of $3 \mathrm{~V}$ or more per cell. In 1985 Akira Yoshino successfully developed a prototype nonaqueous battery, the lithium ion battery [18].

The lithium ion battery quickly revolutionized the electronics industry, and became recognized as an energy powerhouse given its ability to produce a large amount of energy as compared to those aqueous batteries before it. Therefore it is not surprising that Boeing chose the lithium ion battery to power to its 787 Dreamliner, one of the most advanced aircrafts in the history of Boeing.

Boeing's 787 Dreamliner took its first steps to becoming a reality when it launched the 787 program in April 2014, fueled by over sixty customers placing orders for over 1000 Boeing 787 aircraft. The aircraft utilizes the most advanced technology, most notably the recent advances in composite materials. Composite materials are much lighter in weight when compared to their metal counterparts, and Boeing used composite materials for $50 \%$ of the 787 's fuselage and wings. An impressive 1500 aluminum sheets and approximately 50,000 fasteners were saved per section by substituting advanced composite materials [20]. It is worth noting the Eurocopter was issued a patent for the once piece fuselage [2].

The Boeing 787 Dreamliner is equipped with state-of-theart technology that supports what its namesake claims. The aircraft comes equipped with a health monitoring system which enables the aircraft to monitor systems and report needed maintenance to ground crews. Engine technology from both General Electric and Rolls Royce were used to create an engine, according to Boeing, that represents a two-generational gap over previous engine technology. Furthermore, with the volatility of fuel prices, one of the most important features of the Boeing 787 is that it uses $20 \%$ less fuel than comparable aircraft [20].

\section{LITHIUM ION BATTERIES AND AEROSPACE}

It did not take long for Aerospace leaders, such as those at Boeing, to take note of the lithium ion battery's outstanding physical and chemical properties. However, although the general public had been using these batteries for over two decades, the fire hazards and chemical dangers of lithium ion
This research was partially supported by the 2013-2014 Embry-Riddle Aeronautical University Worldwide Faculty Development Research Grant. 
batteries still remained very much unexplored. When Boeing's 787 Dreamliner Aircrafts experienced multiple fires and were finally banned from flying by the Federal Aviation Authority (FAA), the general public began to take note of the need for further investigation into these powerhouses that were quickly becoming the foundation of the evolution of technology.

\section{A. 2013 Boeing 787 Battery Fires}

1) January 7th Incident. Unfortunately the Boeing 787 Dreamliner faced unpredicted hazards. On January 7, 2013 the battery of Japanese Airlines Boeing 787 caught on fire at Boston's Logan International Airport. A maintenance manager noticed that the auxiliary power unit (APU) was not operating, and shortly later a mechanic found that smoke was coming from the APU battery case. Fire crews quickly responded, and found the battery smoldering. Although there was no actual fire seen by anyone directly involved with the incident, the ARFF captain was burned on his neck when, as he recalled, when the battery exploded [6].

Upon further investigation of the battery, there was black residue and white powdery substance found, suggesting that flames were present at some point before the battery was discovered smoldering. This implies that the temperatures in the battery must have exceeded 550 degrees Fahrenheit in order to produce flames [6].

2) January $16^{\text {th }}$ event. A few short days after the first battery fire, the Boeing 787 was in the news again. On January 16, 2013 the battery on Al Nippon Airways caught fire. The passengers aboard the aircraft reported smelling burning plastic before the aircraft ever left the ground. The cause of the Al Nippon Airways incident was a result of a short circuit in the battery: A single cell in the battery failed, causing a domino-effect of short circuit [11],[5]. The short circuit was caused when the separator between the cells became damaged, which caused the electrodes to short-circuit and overheat. A short circuit is dangerous as the resulting increase in temperature can cause a chemical reaction between the highly flammable electrolytes and electrodes, leading to a thermal runaway [12]. Once a lithium ion battery is ignited, it is difficult to put the fire out as the chemicals in the battery, once ignited, produce oxygen [14].

\section{B. Incidents before the Boeing 787 Dreamliner}

Lithium ion batteries have posed fire problems for the aviation industry before Boeing decided to use these powerhouses for their 787 Dreamliner. These problematic events range from the transport of lithium ion batteries as cargo to personal items packed by aircraft passengers to the crash of a United Parcel Service (UPS) plane in Dubai.

1) Cargo: In August 2004 a FedEx cargo box caught fire when lithium ion batteries were packaged along with metal tools. Investigators concluded the metal tools shorted the batteries, thus causing a thermal runaway. This type of fire is and was not unique to FedEx. From June 2006 to present, more than six incidents of possible lithium ion battery fires have been reported that were the suspected result of an external short circuit caused by improper packaging [4]. The question remains as to how many unreported incidents have occurred across the globe.

2) Personal Items: In May 2006 a spare battery pack for a laptop experienced thermal runaway while stowed in the overhead compartment of an aircraft. Several similar incidents where noted since 2006, where laptop batteries overheated and smoked before passengers boarded the aircraft. Moreover, laptop batteries are not the only culprit, thus removing the hypothesis that the laptop design is solely responsible for instigating these fires. The lithium ion battery of a curling iron also experienced thermal runaway, scorching the luggage that contained the curling iron [4].

3) UPS Flight: On September 3, 2010 UPS Flight 6 crashed shortly after take-off from Dubai International Airport. The two crew members, the pilot and first officer, were killed. Twenty-one minutes into the flight the fire alarm sounded at 15:15:15, and crew members immediately put on their oxygen masks and goggles. Two minutes and three seconds after the initial alarm sounded, the pilot was recorded seeking additional oxygen supply. Furthermore, the pilots stated that the smoke made reading the flight instruments impossible. Sadly, UPS Flight 6 went down shortly thereafter [19], [21].

The final investigation report stated that pathological tests indicated the pilot died due to poisoning from toxic fumes. Upon further investigation, it was found that the UPS Flight 6 was carrying undeclared hazardous material: Lithium ion batteries. The final incident report released by the United Arab Emeritus (UAE) General Civil Aviation Authority provides many details that support the fire was caused by the lithium ion batteries in the cargo. Specifically, the report states, "Protection of the critical systems and equipment from the cargo fire damage, in particular the failure of the fire protection liner to limit the exposure of the supplemental oxygen system [SOS] to the cargo fire is a causal factor in the disruption of the oxygen flow to both crew members," [22].

\section{Testing Fire Dangers of Lithium Ion Batteries}

Lithium-ion Batteries were in the making since the early 1900s, and the first rechargeable lithium-ion battery was introduced by Sony in 1991. The use of lithium-ion versus lithium was used due to the instability of lithium under high heat [1]; thus the potential fire hazards associated with lithium batteries has been taken into account for years. Yet even as recent as 2011, there was minimal research available and being conducted on fire hazards of lithium ion batteries on a large scale, such as in aerospace. The most significant reason for this lack of research is that the batteries continue to develop at such a rapid rate, which makes defining a standard for lithium ion batteries nearly impossible [4], [10].

The battery in the January 2013 fire was unique to Boeing. Thus preparing for and predicting possible fires would have required testing on the specific battery used in the Boeing 787; 
neither a cost-efficient nor time-efficient option. Specifically, the Boeing 787 battery consists of eight lithium ion cells, which are aligned in two rows of four cells. The cells are connected in a series, and separated by insulation sheets that provide insulation between the cells and the aluminum casing. Although the material used to construct the lithium ion battery contains nonflammable materials, the electrolyte is flammable and the coatings on the anode and cathode contain components that are chemically reactive [6].

\section{Toxic Risks of Lithium-ion Battery Fires}

Lithium ion battery dangers are still being uncovered as research continues. Lithium ion battery fires are not easy to recreate in a controlled environment, and the behavior of the batteries still remains somewhat unknown. However, there are certain chemicals that scientists and fire safety professionals have identified as a safety hazard with Lithium ion battery fires.

1) Fluoride Fumes: Fluoride Fumes are possible during a Lithium ion battery fire. Carbonyl Fluoride $\left(\mathrm{COF}_{2}\right)$, Hydrogen Fluoride $(\mathrm{HF})$, and Fluorine Gas $\left(\mathrm{F}_{2}\right)$ are all Fluorinated compounds that are minor components of the Lithium ion battery that can be leaked during a fire. There exists a gap in research on how to safely protect fire fighters from these fumes due to the unknown level of dangers these fumes actually present [4]. However the Center for Disease Control does provide a guide for fire safety professionals, supporting the need for continual and additional research.

a) Personnel Safety Precautions when dealing with Fluoride. The Center for Disease Control (CDC) has extensive instructions for firefighters when battling fires where Hydrogen Fluoride fumes are present. The danger primarily exists due to the fact that Hydrogen Fluoride can penetrate skin tissue; thus making it extremely dangerous to those around the fire. The CDC Suggests:

- First Responders and Level A Responders should wear a NIOSH-certified Chemical, Biological, Radiological, Nuclear (CBRN) Self Contained Breathing Apparatus (SCBA) with a Level A protective suit. In addition chemical resistance gloves (both inner and outer), a hard hat, long underwear, and chemical resistance steel toed boots.

- Level B responders have the same requirements as Level A, with less emphasis on skin protection. Level B responders need a suit that is splash-proof, but not airtight.

- Level C Responder, or yellow zone, have the option of wearing long underwear and other garments for protection. However, the need remains for breathing apparatus. Note a yellow zone indicates initial efforts in the red zone have reduced the bulk of the fire dangers.

- Level D Responders, or those responding to the green zone, typically are required to only wear the basic responder gear such as gloves, boots, and work clothes. The Green zone indicates contaminants are eliminated or at safe levels (as with bacteria on skin it is impossible to remove all contaminants as they are naturally occurring) [23].

\section{b) Possible Firefighting Agents}

Proper attire when fighting a fire where HF is present is as important as knowing how to fight the fire to ensure additional dangerous chemical reactions and interactions do not occur:

- For small fires a dry chemical or carbon dioxide is suggested.

- $\quad$ For larger fires, water and alcohol resistant foams are recommended given the potential danger of reactions with standard foams, and HF is highly soluble in alcohol.

- There are further firefighting precautions depending on whether the hazard is anhydrous hydrogen or hydrofluoric acid (both of these compounds are represented symbolically by $\mathrm{HF}$ but differ in strength) [23].

c) Necessary research on suppressing lithium ion battery fires with water. Reference [23] advocates water as an agent to battle large-scale fires where HF is present, but, as with how to properly protect fire professionals, there is a body of research identifying several important research gaps suggesting water may not be the best firefighting agent. The FAA currently suggests traditional sprinkler systems and/or water to battle these fires even though there is little testing to support sprinkler systems as being the optimal method [3]. First and foremost there is a need to identify the necessary sprinkler flow to fully extinguish a powerful fire such as a thermal runaway, if even possible. Current fire-fighting guidance involving consumer goods neglects the fact that these goods could potentially contain lithium ion batteries, which escalates the fire hazard. Foam and water-mist systems should be explored as potential means to combat lithium ion battery fires as these methods and/or other unexplored methods, may prove to me more efficient. Finally, there is very little research on the potential environmental damage caused by the run-off water used to combat lithium ion battery fires. From the final report of the Boeing battery fire on January, it is clear that hazardous materials beyond fluorinated compounds and metal oxides, such as BPA, could possible contaminate the surrounding environment [4].

d. Dangers of the battery cell composition. Clearly risks of a battery fire extend beyond the battery components itself as the materials used in the cell construction are also potential hazards. The battery cells of the Boeing 787 were in contact with internal battery components that are composed of bisphenol (BPA) thermoplastic and sulfide crystalline thermoplastic. BPA thermoplastic begins decomposition at 550 degrees Fahrenheit and the sulfide crystalline 
thermoplastic begins to decompose at 545 degrees Fahrenheit [6].

Recent findings with BPA suggest dangers associated with the thermoplastic when exposed to extreme temperatures. Once thought to cause breast cancer, BPA has garnered a great deal of attention from the public and scientists alike. Generally accepted throughout the research community is the belief that a high amount of heat will cause BPA to escape from the components it construction [7]. Yet the notion of high heat in the medical community is defined to be at 212 degrees Fahrenheit: Boiling Point. In a study on baby bottles, 55\% more BPA leached from bottles when exposed to boiling water. The same study refuted myths that reused bottles were a main source of BPA leaching as old and new bottles performed about the same [8].

Yet the removal of BPA from Boeing's batteries is highly unlikely. BPA thermoplastics are used in the Boeing 787 battery assembly due to their high heat resistance and flame retardant properties. Furthermore BPA thermoplastics are known as good electrical insulators. There has been a great deal of study on polycarbonates composed of BPA and their properties when exposed to high heat. Reference [21] reinforces the attractive properties of BPA, such as a high melting point, lightweight, durable, and high vitrification temperature.

Sulfide crystalline thermoplastic, as mentioned in the battery investigation report, most likely refers to PPS, Poly phenylene sulfide. According to Chevron Phillips' website, PPS "is a polymer made up of alternating sulfur atoms and phenylene rings in a para substitution pattern." [9]. Similar to BPA, PPS has desirable physical properties in the Aerospace industry. Due to the crystalline lattice structure, the melting point of $\mathrm{PPS}$ is $285^{\circ} \mathrm{C}\left(545^{\circ} \mathrm{F}\right)$. Additionally, during combustion PPS will char versus igniting, similar to BPA.

\section{MITIGATING THE CURRENT KNOWN RISKS}

The lithium ion battery fires in Boeing's aircrafts demanded an immediate reevaluation of aircraft safety. Both the UPS event and the battery events on the Dreamliner resulted in Boeing modifying its current aircraft to minimize the reoccurrence of similar events.

\section{A. Boeing Battery Fires}

To mitigate the now very apparent fire risks associated with the lithium ion battery, Boeing engineers took several measures to avoid replacing the battery altogether, which would cause even more changes in the overall electrical structure of the 787 . Moreover, Boeing decided against replacing the lithium ion batteries with nickel-cadmium batteries as the lithium ion batteries are lighter weight and produce more electrical power, which despite the dangers, still is the optimum choice. In order to prevent thermal runaway, Boeing added additional spaces between the battery cells. Boeing engineers developed a $1 / 8$ th inch thick encasing for the batteries to prevent a battery fire from spreading to the plane by inhibiting oxygen $[13,15]$.

\section{B. UPS Cargo Fire (Boeing 747)}

The final report of the UPS Cargo Fire that killed two crewmen in September 2010 had several recommendations to the FAA to protect crewmembers during future flights. The recommendations came after a thorough analysis of testing was completed at Boeings facilities in Seattle and Anchorage. These recommendations included testing cargo storage equipment, installation of fire suppression systems, mandate cargo aircraft to have a method for detecting fires using thermal radiation (which detects fires before smoke alarms), mandate requirement for full face oxygen, and review the Boeing 787 Combi distribution of oxygen [22].

The unpredictable volatile nature of lithium ion batteries was also addressed in this final report. The report recommended amending the instructions for carrying lithium ion batteries. The report specified the need for a dedicated team to lead the study on hazardous cargo, in addition to researching structural-acoustic coupling, and how it relates to lithium ion batteries. In several places, the final report hypothesized that vibration in a possible harmonic form may be the culprit in the high level of lithium ion battery fires. Acoustic emission has been used to study the charge and discharge of lithium ion batteries, and provides evidence that there is structural and morphological impacts on the electrode during the conversion reaction [24].

The tragedy of UPS flight 6 led to the FAA testing many of the safety features involved in transporting cargo. First and foremost initial tests indicate that the cargo container itself has an effect on how long it takes smoke to reach and activate the smoke detector. Containers made from aluminum and polycarbonate and fire-resistant polypropylene were tested. Although the testing lacked enough data to make a strong statistical argument as to which container was better, there were several conclusions that demonstrated the dangers of an aircraft fire:

- Container design does have a significant impact on how quickly smoke detectors are alerted of the fire

- $\quad$ Fire detection may exceed the 1 minute time allowance as stated in Title 14 Code of Federal Regulations (CFR) 25.858(a).

- The growth rate of fires after detected are so rapid that the possibility to subdue the fire is minimal [22].

\section{FUTURE OF LITHIUM ION BATTERIES}

Despite efforts across all industries to minimize the risks associated with the lithium ion batteries, these power-packed efficient energy houses still pose long-term challenges. There is a need for additional research on lithium ion batteries, especially as the number of lithium ion batteries on aircraft is increasing steadily with the continuing advancements of consumer electronic devices. This neglects the aviation industries continued use of these dynamic powerhouses. With current and future space exploration relying on lithium ion batteries, there remains a need for research on how lithium ion 
batteries react in different gravitational fields. For example, the NASA Planetary Data System (PDS) reveals how vital lithium ion batteries are to the mission. There are six instrument hosts that rely on lithium ion batteries for power. The lunar reconnaissance orbiter relies on a lithium ion battery to provide power during the orbit eclipses and the eclipse of the sun by earth [25].

Moreover, the demand for lithium ion batteries by NASA continues to grow, and with the exploration of uninhabited, unexplored space territories, there is a need for creative and extensive testing. Thus why many scientists and researchers are looking towards alternative methods of energy, most of which are considered more environmentally friendly.

\section{A. Alternative Sources of Energy}

At the Manthiram Laboratory at the University of Texas at Austin, a research team is dedicated to creating a safer and more power lithium ion battery. The group describes its mission as:

With traditional lithium-ion batteries, our group is focused on high-capacity layered oxide, high-voltage spinel, and polyanion cathodes as well as nanocomposite alloy anodes based on antimony, tin, and silicon. The major focus is increasing the cell energy density beyond the current levels while realizing good safety and long cycle life by compositional, morphological, and surface controls through novel, low-cost synthesis approaches [16].

The team at the Manthiram Laboratory is also researching technology beyond the Lithium Ion Battery. One such example is the sodium-ion battery, which explore the use of new cathodes and nanocomposite alloy anodes [16].

Researchers at Rice University and the City College of New York have been working on green efforts that are literally green. Researchers have found that the madder plant (scientific name Rubiatinctorum) contains pupurin; an organic dye that can be used to create a natural cathode for lithium ion batteries. Unlike cobalt cathodes used in the production of lithium-ion batteries, manufacturing purpurin cathodes can be completed at room temperature, a relative generous cost savings. Furthermore purpurin may be found in agriculture waste, thus making itself a product of recycling [17].

\section{CONCLUSION}

Lithium ion batteries are an efficient source of energy, but the many unknown risks associated with these powerful sources of energy create potentially dangerous situations. Lithium ion battery fires are becoming more prevalent with their increased use in aviation, as seen in the Boeing 787 incidents. The methods to battle these fires are unexplored as thermal runaway is difficult to recreate in a controlled situation.

Now that lithium ion batteries have become a staple in the aviation industry, from use on the planes to cargo to a drastic increase in consumer electronic devices that are being carried on and stowed on aircraft each day, the need for further research and alternatives are vital. Boeing has done a laudable job spearheading advancements in aviation, and it would be highly beneficial for aerospace scientists to work closely with those in other industries who have been researching alternatives for the use in consumer electronics. Furthermore, there is a strong need and demand for more environmentally friendly energy sources, and this would be a benefit to all parties involved, and help garner much needed community support for the advancement of aviation and aerospace.

\section{ACKNOWLEDGMENT}

The author thanks the Embry-Riddle Aeronautical University Worldwide team, as they are dedicated to providing superior education to continue the rapid advancement of aviation and aerospace. The author also wishes to thank Mr. Mark Severson of Boeing for his continued insights and suggestions, in addition to his welcoming hospitality that creates a joyous research environment. Finally, the author sends a tremendous amount of gratitude to Mrs. Michelle Severson for her continued dedication to the health, safety, and protection of United States Navy personnel across the globe.

\section{REFERENCES}

[1] Buchmann, Issac (July, 2010). Lithium-ion Safety Concerns [Online]. Available: http://batteryuniversity.com/learn/article/lithium_ion_safety_concerns.

[2] Eurocopter deutschland $\mathrm{GmbH}$; patent issued for fuselage structure made of composite material. Journal of Engineering, , 5481. 2014.Retrieved From: http://search.proquest.com.ezproxy.libproxy.db.erau.edu/docview/14775 54641 ? accountid=272

[3] FAA Aviation Maintenance Technician Handbook-Airframe (FAA-H8083-31), 2012. Availabale: http://www.faa.gov/regulations_policies/handbooks_manuals/aircraft/am t_airframe_handboo k/media/ama_Ch07.pdf.

[4] Kahn, Michael; Long, Richard; Mikolajczak, Celina; White, Kevin. Lithium Ion Battery Fire Hazards and Use Assessment Final Report. 2011. Available: /www.nfpa.org/ /media/Files/Research/Research\%20Foundation/Resear ch\%20Foundation\%20reports/Hazardous\%20materials/rflithiumionbatte rieshazard.pdf

[5] Post Staff Report. Japan probe suggests excess voltage in Boeing 787 battery. The New York Post. (2013, January 18). Available: http://nypost.com/2013/01/18/japan-probe-suspects-excess-voltage-inboeing-787-battery/

[6] National Transportation Research Board (2013). Interim Factual Report. Case Number DCA13IA037. Available http://www.ntsb.gov/investigations/2013/boeing_787/DCA13IA037\%20 interim\%20factual\%20report.pdf

[7] Sarah Q To, Yuet-Kin Leung, Shuk-Mei Ho, and Colin D Clyne Endocrine disruption of the epigenome: a breast cancer link Endocr Relat Cancer 21 (2) T33-T55, doi:10.1530/ERC-13-0513 first published on 14 February 2014

[8] Szabo, Liz. (2008, January 29). Heat causes chemical to leach from Plastic. USA Today. Available http://usatoday30.usatoday.com/news/health/2008-01-29-plasticchemical_N.htm

[9] Chevron Phillips (2013). What is PPS. Available: http://www.cpchem.com/bl/rytonpps/en-us/Pages/WhatIsPPS.aspx

[10] Jacoby, Mitch (2013). Assessing Safety of Lithium Ion Batteries. Chemical and Engineering News. Vol 1, Issue 6. Avialable: 
http://cen.acs.org/articles/91/i6/Assessing-Safety-Lithium-IonBatteries.html

[11] Rushe, D. (2013, Feb 21). Boeing battery fire blamed on wiring fault The Guardian.

Available: http://search.proquest.com.ezproxy.libproxy.db.erau.edu/docview/12910 67054? accountid $=27203$

[12] Glen, Patrick. (2012) Preventing laptop fires and "thermal runaways." Retreived from http://science.energy.gov/discovery-andinnovation/stories/2012/127035/

[13] Boeing targets battery problems. (2013, Jan 31). Irish Times. Retrieved from:

http://search.proquest.com.ezproxy.libproxy.db.erau.edu/docview/12826 60432? accountid=27203

[14] Negishi, Mayumi and Kelly,Tim (January 15, 2013). Boeing shares fall as Japanese airlines ground Dreamliners after emergency landing. Reuters. Available: http://business.financialpost.com/2013/01/15/allnippon-airways-operated-boeing-787-makes-emergency-landing-injapan-after-smoke-seen-in-cabin-report/

[15] Mecham, Michael (2013). Boeing battery fix preserves 787 systems Aviation Week. Available: http://aviationweek.com/awin/boeing-sbattery-fix-preserves-787-systems

[16] Manthiram Laboratory, the University of Texas at Austin. Available: http://www.me.utexas.edu/ manthiram/research.htm\#clean

[17] Williams, Mike (2012). Rice cultivates green batteries from plant. Available: http://news.rice.edu/2012/12/11/rice-cultivates-greenbatteries-from-plant-2/

[18] Yoshino, A. (2012), The birth of the lithium-ion battery. Angew. Chem Int. Ed., 51: 5798-5800. doi: 10.1002/anie.201105006

[19] General Civil Aviation Authority United Arab Emirates. September 03, 2010. Air Accident Investigation Interim Report Boeing 747. Available: http://www.gcaa.gov.ae/en/ePublication/admin/iradmin/Lists/Incidents\% 20Investigation \%20Reports/Attachments/16/2010Interim\%20Report\%20B747-400F\%20-\%20N571UP\%20\%20Report\%2013\%202010\%20-\%20Rev\%201.pdf

[20] $787 \quad$ Dreamlinger.

Available: http://www.boeing.com/boeing/commercial/787family/787-8prod.page

[21] Szymański, A, Wasiak, W.(2006). Micellar liquid chromatography inanalysis of bisphenol A. The Jubilee XXXth Symposium: Chromatographic Methods of Invesigating Theorganic Compounds. Available: http://chromatographia.us.edu.pl/2009/annex2006.pdf
[22] General Civil Aviation Authority United Arab Emirates. September 03, 2010. Air Accident Investigation Final Report Boeing 747. Available: http://www.gcaa.gov.ae/en/ePublication/admin/iradmin/Lists/Incidents\% 20Investigation \%20Reports/Attachments/40/2010-2010\%20 \%20Final\%20Report\%20-\%20Boeing\%20747-44AF\%20\%20N571UP\%20-\%20Report\%2013\%202010.pdf

[23] CDC (2014) Emergency Response Card: Hydrogen Flouride/Hydrofluoric Acid. (2014, August 8). Available: http://www.cdc.gov/niosh/ershdb/EmergencyResponseCard_29750030.h tml

[24] Villevieille, M. Boinet L. Monconduit (2010). Electrochemistry Communications Volume 12, Issue 10, Direct evidence of morphological changes in conversion type electrodes in Li-ion battery by acoustic emission C. Pages 1336-1339.

[25] Planetary Data System (2014). Available: http://pds.nasa.gov/tools/datasearch/search.jsp?q=lithium+ion+battery

Dr. Heather L Garten (Stetson University `00-Emory Univesrity `05) This author obtained her PhD in Mathematics from Emory University in 2005. Her dissertaion was in topology entitled Satellite Graphs. In 2000 this author graduated from Stetson University with a double major in mathematics and economics.

She is currently an assistant professor with the college of arts and sciences at Embry-Riddle Aeronautical University Worldwide. Previously she worked at the Department of Defense, and taught at Emory University while obtaining her $\mathrm{PhD}$. She has been featured in the Airport Council International-North America (ACI-NA) Magazine Centerlines, The Journal of American Academy of Business, Cambridge, and interviewed on several occasions by the Fort Worth Star-Telegram for her work in Aerospace and STEM.

Dr. Garten is a member of ACI-NA, and is currently serving as an expert panelist for Airport Cooperative Research Program Practices to Develop Effective Stakeholder Relationships at Smal Airports. Dr. Garten is a member of the Center for Undergraduate Resarch (CUR), and serves as a senator for the Embry-Riddle Aeronautical University Worldwide senate. Dr. Garten is a member of the Center for Aviation and Aerospace Leadership (CAAL), where she is a regular contributor to the CAAL Blog. Dr. Garten is an invited speaker for the Ronald McDonald House Charities, and continues to increase volunteerism through her passionate speeches. 